\title{
Reduzindo danos e ampliando a clínica: desafios para a garantia do acesso universal e confrontos com a internação compulsória ${ }^{1}$
}

\author{
Tadeu de Paula Souza \\ Universidade de Campinas, Campinas, SP, Brasil. \\ Sergio Resende Carvalho \\ Universidade de Campinas, Campinas, SP, Brasil.
}

\begin{abstract}
Resumo
Neste trabalho problematizamos o desafio de cumprimento do direito universal ao acesso em saúde para usuários de álcool e outras drogas no Brasil. Para isso apresentamos alguns vetores que interferem na produção de saúde para esta população. Analisar os desafios do campo da saúde nos conduziu à necessidade de compreender alguns vetores construídos historicamente e ao mesmo tempo nos conduziu à necessidade de avaliar como estes vetores se atualizam no contemporâneo. Além destes aspectos cabe ressaltar o trabalho conceitual que propôs uma análise histórica do conceito de universalidade e dos diferentes sentidos que ele pode assumir.
\end{abstract}

Palavras Chave: Drogas, Universalidade, Rede de Saúde, Redução de Danos.

\begin{abstract}
In this paper we problematize the challenge of fulfilling the right to universal access to health care services by alcohol and other drugs users in Brazil. To do that, we present some factors that interfere with the health status of these persons. Analyzing the challenges in the health field led us to the need to understand how these factors were historically constructed and at the same time how they are contemporary updated. Besides these aspects it is worth noting the conceptual work that proposed a historical analysis of the different meanings that the concept of universality can take on.
\end{abstract}

Key Words: Drugs, Universality, Health Care Sistem, Harm Reduction.

\section{Resumen}

En este trabajo problematizamos el desafío de cumplir el derecho universal al acceso a la salud para usuarios de alcohol y otras drogas en Brasil a partir de la perspectiva de la reducción de daños. Para esto, presentamos algunos vectores que interfieren en la 
producción de salud para esta población. Analizar los desafíos del campo de la salud nos condujo a la necesidad de comprender algunos vectores construídos históricamente y, al mismo tiempo, la necesidad de evaluar como estos vectores se actualizan en lo contemporáneo. Además de estos aspectos, cabe destacar el trabajo conceptual que propuso un análisis histórico del concepto de universalidad y de los diferentes sentidos que puede asumir.

Palabras clave: Drogas, Universalidad, Red de Salud, Reducción de Daños.

Perspectiva da redução de danos

Uma importante estratégia de redução de danos surgiu a partir de iniciativas de troca de seringas, realizadas por uma associação de usuários de drogas (a Junkiebonden) no início dos anos 80, na Holanda (Bastos, 2003). Diante das contaminações de hepatites virais causadas pelo compartilhamento de seringas entre usuários de drogas injetáveis, grupos de usuários passaram a criar estratégias para se proteger. Trata-se de um pequeno grupo que conciliou o desejo de continuar a usar drogas com a construção de estratégias de cuidado de si e dos outros. Esta experiência local inaugurou novas possibilidades de se falar sobre as drogas e sobre os usuários de drogas. Usuários que queriam se cuidar para continuar vivos e usando drogas iniciaram a construção de um novo plano discursivo sobre si e suas experiências, antes silenciado e posto na invisibilidade.
Como afirmam Foucault e Deleuze (1986):

\begin{abstract}
Ora o que os intelectuais descobriram recentemente é que as massas não precisam deles para saber; elas sabem perfeitamente, claramente, muito melhor do que eles; e elas o dizem muito bem. Mas existe um sistema de poder que barra, proíbe, invalida esse discurso e esse saber. (pp. 71)
\end{abstract}

Este tipo de relação com as drogas deveria ficar invisível pelas tecnologias de poder que querem a todo custo associar uso de drogas a desejo de morte, descuido, criminalidade, ruína e doença. Como veremos, tecnologias estas agenciadas pela lógica da abstinência, para a qual o uso de drogas e o cuidado de si são atitudes incompatíveis. O que a redução de danos trouxe a contrapelo deste paradigma foi a dimensão singular da experiência do uso das drogas, evidenciando usuários que desejavam continuar a usá-las. Ao possibilitar que 
os usuários falassem em nome próprio a redução de danos também tornava legítimas estas experiências. $\mathrm{O}$ que usuários de drogas dizem, pensam e sentem em relação ao uso de drogas? E o que dizem, pensam, sentem e fazem quando desejam continuar a usá-las? São questões que foram inspiradoras do movimento da redução de danos e que constitui uma perspectiva de análise sobre o fenômeno das drogas.

No regime de criminalização e condenação moral dos usuários de drogas, estes, quando convocados a falar, são sempre na condição de culpados e arrependidos, sendo o primeiro passo o reconhecimento da doença, e o segundo a busca da cura. São convocados a falar somente na condição de doentes, sejam ex-usuários ou candidatos a ex-usuários. Uma segunda possibilidade seria falar na condição de réu ou criminoso. Não queremos dizer com isso que os usuários de drogas estivessem absolutamente silenciados. Nas pequenas rodas $\mathrm{e}$ no intimo $\mathrm{da}$ privacidade ilícita as trocas de experiências sempre correram soltas. Mas esta perspectiva, a dos usuários de drogas que vivem a usá-las, nunca pode ser tomado como um discurso politicamente válido.
A partir da mundialização da epidemia de HIV/AIDS a redução de danos foi inserida num novo circuito institucional. A Organização Mundial da Saúde (OMS) incluiu as estratégias de Redução de Danos (RD) no repertório de ações de combate a esta epidemia. As orientações da OMS e os financiamentos vindos do Banco Mundial possibilitaram que em muitos países a redução de danos fosse adotada como uma das ações de prevenção (WHO, 1993 apud Wodak). O anteparo institucional criado pelas políticas mundiais de HIV/AIDS possibilitou que questões como direitos dos usuários passassem a ser pautadas localmente. Desse modo as questões trazidas pela $\mathrm{RD}$ a respeito das experiências de pessoas que desejam usar drogas, passou a se tornar tema de debate político em torno de busca de garantia de direitos humanos.

A RD passou a ativar um novo movimento, mesmo que minoritário, de defesa pelo direito ao uso de drogas, enquanto um problema não só de ordem pessoal, mas, sobretudo, como uma afirmação política. Usuários de drogas falando e agindo em nome próprio, criando estratégias de cuidado que incluem a possibilidade de usar drogas, produziram um curto-circuito frente às políticas hegemônicas que tendem os 
criminalizam. E para que fosse possível constituir campos políticos, a RD propõe ao invés de regras coercitivas, que cada usuário constitua para si regras de cuidado, regras facultativas. (Foucault, 2006; Souza, 2007).

A RD se tornou um dispositivo em que os usuários de drogas podem falar em nome próprio. Essa possibilidade inaugurada constituiu uma perspectiva de análise porque através dela podemos nos aproximar dos usuários de drogas e assim acompanhar o que eles dizem, sentem e fazem. Assim a RD vai deixando de ser um conjunto de estratégias e vai se tornando um conceito que abrange diferentes estratégias. A RD vai se tornando um modo de se pensar, falar, sentir e agir sobre as drogas: uma perspectiva.

\section{Para além das polaridades}

Acompanhando um caso em uma unidade básica de saúde uma equipe de referência nos solicitou apoio para elaboração de um projeto terapêutico de uma senhora de aproximadamente sessenta anos que abandonara o tratamento de diabetes em função da dependência com o álcool. ${ }^{2}$ Ao fazermos uma visita domiciliar a senhora disse que abandonara o tratamento da diabetes porque toda vez que ia a unidade os profissionais de saúde diziam que ela tinha que "parar de beber". Essa senhora era arrimo de família (três filhos e cinco netos) e, para esta senhora a bebida, como ela mesma comentou, não era seu principal problema. A dificuldade com os filhos e netos era sua principal queixa $\mathrm{e}$ apontava para uma difícil situação existencial. Ao ser impelida a parar de usar álcool a senhora se sentia pessoalmente descriminada e não acolhida na sua singularidade, na sua história, no seu desejo e nas suas dificuldades. Dessa forma, em nome de uma norma (estar abstinente), outros problemas de saúde não eram acompanhados. Fora as simplificações que uma breve exposição pode produzir, queremos extrair aspectos que não se distanciam tanto das realidades cotidianas dos serviços de saúde.

A dificuldade com os filhos e netos era sua principal queixa e apontava para uma difícil situação existencial. Ao ser impelida a parar de usar álcool, essa senhora se sentia pessoalmente discriminada e não acolhida na sua singularidade, na sua história, no seu desejo e nas suas dificuldades. Em nome de uma norma (estar abstinente), outros problemas de saúde não estavam sendo acompanhados. Não desconsiderando as 
simplificações que essa breve exposição pode produzir, pretendemos com ela apenas extrair aspectos que não se distanciam tanto das nossas realidades em saúde.

A abstinência, como condição para o acesso ao serviço, foi posta pela equipe de saúde da família, de modo muito distinto do modo como ela é posta em clínicas e serviços especializados. Mas em ambos os casos, a abstinência comparece como regra, norma que define uma fronteira entre o dentro e um fora do sistema e ao mesmo tempo um limite entre a cura e a doença, entre o normal e o patológico. São estas imagens polarizadas que vemos começarem a se formar: contra ou a favor; sim ou não; tudo ou nada; abstinente ou drogadito; para no limite nos esbarramos com a dualidade bem e mal. A polarização produzida no campo das drogas reconhece duas posições e possibilidades extremas. É neste jogo de polarizações e antagonismos que a RD acaba muitas vezes confundida com o polo oposto a abstinência $\mathrm{Se}$ à abstinência corresponderia a faceta do "NÃO AS DROGAS", a RD acabaria sendo arrastada para a faceta oposta, a do "SIM AS DROGAS". Acusada de incentivar o uso de drogas, a RD se enredada neste esquema binário em que o campo da justiça define o que pode e o que não pode no campo da saúde, especificamente no que diz respeito a atenção aos usuários de álcool e outras drogas. É esse tipo de imagem formatada que faz com que uma parcela da sociedade civil, gestores, juristas, familiares, acreditem que a $\mathrm{RD}$, por não dizer "NÃO AS DROGAS", estaria inevitavelmente dizendo "SIM AS DROGAS". Associando-a com a imagem de um bando de usuários usando drogas livremente pelos estabelecimentos de saúde. Se por um lado esta operação não passa de um ataque banal a $\mathrm{RD}$, por outro ela revela uma característica emergente que a RD traz para o campo das drogas: fazer surgir novas regras diferentes da regra da abstinência e de atrelar a saúde a uma terceira via que possibilite escapar do esquema jurídico do contra ou a favor, do lícito e ilícito.

Quando a abstinência é tomada como regra única e superior, ela acaba por destituir outras possibilidades de regras. Isolada como única regra, torna outras possibilidades de regras em nãoregras, logo, num "vale tudo". Quando um determinado regime de saber-poder erige o "vale nada" como condição, toda e qualquer alternativa a esta proposta hegemônica é taxada como "vale tudo". Mas é exatamente neste ponto que a $\mathrm{RD}$ se ergue como uma 
alternativa potente a este regime de saber-poder, pois para reduzir danos não pode "valer tudo", não se reduz danos com enunciações que se alinhem com a lógica do "liberou geral".

Antes de se tornar uma norma médica e jurídica, a abstinência era um a norma religiosa. Esse dualismo maniqueísta antes de ser operado pelo binarismo da lei (lícito e ilícito) ou pela norma médica (normal e patológico) foi operado pelo dualismo religioso (bem e mal). Estes três âmbitos de construção de práticas sobre o corpo e sobre a vida operam por polarizações. O ideal do mundo sem drogas congrega, no contemporâneo, regimes de saber-poder dentro de novas tecnologias de governo das condutas.

A saúde como campo de saberpoder não se encontra fora destas tecnologias de governo, podendo muitas vezes estar a elas submetida, reproduzindo sua lógica. Mas pode também estar traçando linhas de resistência a essa lógica. A RD não contesta a abstinência como meta possível e desejável, mas a abstinência como regra absoluta, evidenciando que entre o "SIM" e o "NÃO" existe uma terceira via: o "COMO”? Arguir como podemos em sociedade viver com as drogas não é uma posição a favor ou contra as drogas, mas uma posição que busca apontar para os cuidados que devemos ter em relação às experiências com as drogas. Esse tipo de postura tenta desconstruir a noção de que as drogas são um problema em si, recusando a substancialização de um problema complexo que transforma uma substância em uma entidade quase com vida própria: as drogas!

Certa vez andando de ônibus sentei ao lado de uma senhora e logo vimos um rapaz morador de rua cambaleando e tropeçando numa tentativa de seguir caminhando. A senhora assustada exclamou: "veja o que o crack faz com as pessoas!". Muitos outros signos, como a miséria, desemprego, desassistência, modos de vida, etc. foram subtraídos por um único signo - o crack - e numa operação cognitiva que permitia tornar localizável um problema complexo, a senhora resumiu um problema multicausal num problema de causa única: as drogas como causa. A pergunta que me ficou foi se esta constatação deixava a senhora perplexa ou se de certa forma a deixava mais aliviada por poder localizar o problema. A eleição das drogas como um grande mal da atualidade permite concentrar esforços na sua eliminação e no seu combate gerando uma polarização entre os que 
estão a favor e os que estão contra, sendo excluída uma terceira via.

Veremos como a RD ao se opor a alternativa SIM x NÃO (as drogas) recoloca o problema das drogas fora do esquema polarizado e maniqueísta que busca reduzir um campo de múltiplas possibilidades em duas categorias rígidas. No diagrama de poder em que os enunciados de "NÃO AS DROGAS" comparecem como oposição aos enunciados de "SIM AS DOGAS", mais do que a formação de posições contrárias evidenciam-se complexas tramas de controle da vida. Nesse sentido o SIM e NÃO como única alternativa possível de apreensão deste fenômeno, que fecham um plano de múltiplas possibilidades num campo antagônico, são códigos de um mesmo regime de saber-poder. Numa primeira mirada mais superficial podemos acabar por concluir que o vale tudo e o vale nada são posições contrárias, mas precisamos olhar para uma dimensão mais genealógica deste problema e captar o instante em que as aparentes oposições formam um único esquema que captura por contradição, por polarização, por antagonismos. Se não formos capazes de sair dos antagonismos e polarizações, estaremos enredados nas tramas desta forma de controle. Se não formos capazes de criar caminhos alternativos ao SIM/NÃO estaremos aprisionados em um esquema bipolar.

Quando uma equipe de saúde ou mesmo um profissional de saúde, ao atender uma pessoa usuária de drogas, coloca para si a tensão "sou a favor" ou “contra as drogas", está formulando o problema da abordagem e acolhimento a este usuário segundo uma perspectiva que o colocará num antagonismo (combate ou simples aceitação) com a experiência de uso de drogas que está em curso na vida deste usuário. Em outras palavras, a clínica será conduzida a partir de um problema que foi mal formulado. O combate ou a simples aceitação são formas de não entrar em contato com a experiência em curso. A direção proposta pela redução de danos, de acolher o outro na sua diferença, atualiza um sentido de universalidade aliado à dimensão singular da experiência com o uso de drogas que cada um pode ter.

\section{Individualização do fracasso: da abstinência à recaída}

Atualmente há um movimento de denúncia e análises do fracasso da guerra às drogas. Autoridades como Bill Clinton e Fernando Henrique Cardoso ${ }^{3}$, dentre outros, avaliam que a guerra as 
drogas não alcançaram seu objetivo inicial e que por isso é preciso revê-la. A que outros objetivos, que não o fim das drogas, a política de guerra as drogas se destina? A finalidade da guerra as drogas não era simplesmente a extermínio do consumo e produção de drogas sobre o planeta. Como uma estratégia inviável de saída se fortaleceu e ganhou mais consistência na justa medida em que seus objetivos expressos fracassavam?

Apontar as contradições da guerra às drogas não é nada mais do que identificar um estado de coisa, não podendo ser o fim de uma análise crítica. Sobretudo numa modalidade de governo em que contradição não é sinônimo de fraqueza, nem mesmo de fracasso. Não se trata de abordar a história a partir dos erros e contradições, mas de buscar identificar que regimes de verdade dão sustentação as falhas e contradições. É nesse sentido, que Foucault (2008) propõe substituir a lógica da dialética pela da estratégia. A lógica da dialética é uma lógica que põe os termos contraditórios para definir uma solução unificadora, que supera as contradições e constituiu uma unidade. A lógica das estratégias é uma lógica que permite analisar os meios pelos quais termos heterogêneos são conectados e que mesmo conectados não deixarão de ser díspares entre si. "A lógica da estratégia é a lógica da conexão do heterogêneo e não a lógica da homogeneização do contraditório.” (pp. 58).

Racismo e teoria da degenerescência foram as bases conceituais para que a medicina impusesse desde o século XVIII a internação compulsória como meio para tratamento. As primeiras iniciativas anti-drogas de interesse internacional foram capitaniadas pelo bispo e advogado Charles Brent após sua chegada na Filipinas. Tido como um dos principais articuladores da Comissão Internacional do Ópio, se vê em seu discurso oficial a articulação entre moral religiosa e racismo, verificada na carta enviada pelo bispo ao presidente Roosevelt, em que condenava um governo cúmplice da busca de ópio por raças degeneradas. (Escohotado, 2005; Araujo 2012). O problema geral do racismo e das raças degeneradas foi o alicerce biopolítico que sustentou a associação entre drogas e ameaça a espécie humana. O Estado Moderno não inventou o racismo, mas seu uso dentro do regime biopolítico ganha contornos inovadores. A associação entre hábito cultural (de "raças inferiores") e ameaça geral a vida foi a matriz discursiva para que diversas 
tecnologias de poder fossem agregando volume e adensando uma verdade sobre as drogas. Numa sociedade em que a vida é objeto de intervenção política, o direito a morte e a restrição da vida só pode ser atribuído a alguma coisa que ameaça a própria vida, a vida da espécie humana. A noção de raça estabelece um corte no contínuo biológico da espécie humana, uma diferenciação que se hierarquiza entre as raças inferiores e raças superiores, entre as raças que devem viver $\mathrm{e}$ as raças que devem morrer. "Isso vai permitir ao poder tratar uma população como uma mistura de raças ou, mais exatamente, tratar a espécie, subdividir a espécie de que ele se incumbiu em subgrupos que serão, precisamente, as raças" (Foucault, 2005, p. 395)

Apesar de séculos de ineficiência e fracasso a proposta de internação compulsória continua a ressurgir nos corredores que ligam o poder legislativo ao poder executivo, inclusive na atual cena da política brasileira. Por um lado isso torna evidente que é em nome da vida que o Estado revigora o poder soberano de sequestro e morte de parcelas específicas da população. Por outro lado isso permite avançar no entendimento da função estratégia que a norma geral da abstinência cumpre para a biopolítica das drogas.

Se novamente a internação compulsória nos conduz para uma estratégia que fracassa em seus objetivos é porque precisamos entender sua função estratégia para além dos interesses explícitos. Se uma estratégia fracassa há séculos e ainda mantém um valor de uso para a sociedade é porque esta estratégia cumpre uma função que se ajusta e se potencializa no próprio fracasso.

Teremos que identificar como as falhas, as contradições e as fissuras são os meios pelos quais se governa. Dito de outra forma, será preciso apresentar estas falhas, não como ponto fraco do atual sistema de governo das condutas, mas como o ponto forte, o meio pelo qual o governo dos homens aumenta o poder de definir condutas e normalizar a vida.

Quando Foucault (1977), por exempla extrai da suposta falha das prisões, não uma análise da sua função específica, mas uma análise da sua posição estratégica dentre de um regime de poder, ele extrapola uma análise das falhas e das contradições como dados finais, mas como meios para se buscar outras finalidades que se operacionalizam além do discurso criminológico, ou seja, além do 
“cientificamente" dito. Numa análise sobre o regime disciplinar Dreyfus e Rabinow (2010) trazem a seguinte análise do pensamento foucaultiano a respeito do fracasso das prisões:

\begin{abstract}
A questão não é: porque as prisões fracassaram? Ao contrário, a que outros objetivos serviram seu fracasso, que talvez não seja um fracasso? A resposta de Foucault é direta: "Seria necessário então supor que a prisão e, de um modo geral, sem dúvida os castigos, não fossem destinados a suprimir as infrações, mas, antes, a distingui-las, distribuí-las, utiliza-las; que eles visem não tanto a tornar dóceis aqueles que estão prontos para transgredir as leis, mas que tendam a organizar as transgressões as leis em uma tática geral das sujeições.” ${ }^{4}$ As penitenciárias, e talvez todo poder nomalizador funcionaram onde eram apenas parcialmente bem sucedidos. (pp. 256-
\end{abstract} 257)

Mesmo que uma pequena parcela, dentre os que são internados para tratamento, continuam abstinentes após este processo, continua-se havendo propostas de internação compulsória para usuários de drogas. Para que esse processo seja eficiente em seu poder discursivo de produção de subjetividade, esta maquinaria do fracasso precisa se apoiar na gravidade do caso para o qual a noção de recaída cumpre um papel fundamental. A recaída comparece como medida não do fracasso da instituição, mas como medida da fraqueza individual e gravidade da doença, reforçando a necessidade de um exercício de poder que exclui a opção, opinião e desejo do sujeito doente. O que seria a recaída? Ao ser um meio de individuar o fracasso e índice da gravidade da doença, a recaída ganha estatuto de uma verdade sobre a natureza deste indivíduo. A recaída só se coloca num sistema de signos e valores governados pela lógica de que o objetivo final desta estratégia é a vida livre de drogas.

Por que o retorno ao uso de drogas após um período de abstinência tem que ser significado como uma queda? Não poderia este movimento ser significado como um retorno? A noção de queda tem, assim como a noção de abstinência, um fundamento religioso. Recair é, antes de tudo, uma queda da alma que se deixou levar pelas tentações pecaminosas. Quando a saúde adota estes termos como signos que dão sentido e constituem um regime de valores e de verdades, entre as instituições de saúde e as instituições religiosas passa a se constituir uma contiguidade. A constituição de uma rede pastoral-medicalizada conecta uma infinidade de termos heterogêneos que 
definem uma rede de governamentalidade da população. A recaída se torna o próprio motor de um ciclo vicioso, de um sistema que se alimenta da falha na medida em que individualiza. A dependência química, como doença crônica incurável, recoloca nas mãos da medicina o poder de dependência infindável, antes realizada pelo poder pastoral religioso. (Foucault, 2009) Ao definir um diagnóstico que retira do sujeito o poder de decisão sobre si, a medicina define uma linha de conexão com a segurança e com o poder de polícia.

A abstinência deve continuar a ser uma busca, mesmo que para isso se use a força. Se do ponto de vista de efetivação da cura, a internação compulsória é um fracasso, do ponto de vista de esquadrinhamento e normalização do socius esta medida continua a ser potente, servindo como regime de visibilidade e dizibilidade sobre as experiências com as drogas.

Numa sociedade que construiu as drogas como figura de ameaça da segurança individual e das famílias, o fracasso da medida repressiva será apenas índice de que esta repressão não está sendo suficientemente repressiva. $\mathrm{O}$ fracasso não gera um recuo da medida adotada, mas sim uma intensificação da mesma. A abstinência tem sua sustentação não na sua efetividade, mas no seu poder simbólico do ideal de uma sociedade livre desta ameaça. A internação compulsória, sendo um mix de punição e medida de tratamento, mantém provisoriamente este ideal. A recaída é um ponto fundamental deste circuito que se fortalece na medida em que fracassa. É sob o signo da doença, e de sua gravidade que o fracasso será creditado, sendo a recaída uma manobra de individualização do fracasso. Passa-se a se pensar em adequação do sistema de exclusão, seu aperfeiçoamento, sua sofisticação para que um dia este estado seja permanente para um conjunto maior da população internada. Abstinência como meta, dependente químico como diagnóstico e internação compulsória como medida são acionados como um círculo vicioso que individualiza o fracasso e ao mesmo tempo possibilita uma intervenção de corte populacional, um regime de saberpoder-subjetivação que é ao mesmo tempo individualizante e totalizador: uma biopolítica das drogas. 


\section{Universalidade e clínica ampliada:} confrontos e encontros entre redução de danos e abstinência

Partimos do esforço para que o tema das drogas seja um ponto de problematização do próprio SUS, por um lado, e, por outro, faremos com que os princípios e diretrizes do SUS possam fortalecer e qualificar a discussão sobre as políticas de drogas. Interessa-nos, igualmente, discutir o SUS e discutir a especificidade do campo das drogas. $\mathrm{E}$ faremos isso tratando estas duas instâncias como dobras que não se contém inteiramente: o tema das drogas não cabe inteiramente no SUS; os problemas vividos pelos usuários de drogas no sistema de saúde são constituídos por forças que atravessam, interferem e redirecionam a política do SUS. Por outro lado, o SUS, não se resume a problemática das drogas e enquanto campo em construção pode atualizar e reforçar um conjunto de forças (e relações de poder) constituídas historicamente, como pode produzir mudanças e alternativas potentes para a vida dos usuários de drogas. É dentro deste jogo de forças que inserimos a Redução de Danos, como um conceito que tem uma face voltada para o SUS e uma face voltada para outras forças políticas, que uma vez constituídas fora do SUS, podem interferir no rumo do próprio SUS.

Reduzir dano como objetivo das ações de saúde para usuário de crack, álcool e outras drogas indica que a RD investe sobre as experiências com as drogas que se tonaram danosas. Disso se subtrai três conclusões lógicas: i) a primeira é que a $\mathrm{RD}$ parte do fato empírico de que nem todas as experiências com as drogas são danosas; ii) a segunda é que nem todos que têm relações danosas com as drogas desejam parar de usar drogas; iii) que os danos podem ser de diversas ordem, cabendo ações em saúde que atentem para esta diversidade e possam trabalhar com a especificidade de cada caso. (Tedesco \& Souza, 2009)

Parar de usar drogas como meta terapêutica, se torna uma possibilidade e não a única meta para todos os casos. Esse é o primeiro confronto direto da RD com a abstinência: não se trata de um confronto com a abstinência como meta possível, mas da abstinência como regra absoluta.

Quando a abstinência comparece como uma norma médica e jurídica (Souza 2007; Passos \& Souza, 2011) que define como campo de possível para o tratamento de usuários de drogas, a suspensão necessária do uso de drogas, o campo da saúde é 
posto em contradição, uma vez que exclui as pessoas que não aceitam a abstinência como condição e meta para o seu tratamento; sejam estas pessoas conscientes ou não de sua posição subjetiva e desejante. $\mathrm{O}$ que fazer com estas pessoas? Negá-las cuidado em saúde? Forçá-las ao tratamento? Propor alternativas a abstinência? É o sentido de universal que entra em cena, uma vez que o "todos têm direito" entra em conflito com o "todos devem parar de usar drogas para terem direito". Precisamos analisar os sentidos de "todos" operados pela universalidade e pela abstinência como norma absoluta. Os modos de apropriação do princípio de universalidade ganham sentidos distintos a partir das diferentes normas que efetivam o acesso e o cuidado em saúde. Quando falamos que a abstinência é uma norma, precisamos analisar o agenciamento universalidadeabstinência como um operador das relações em saúde.

Quando as práticas de atenção à saúde são direcionadas pela abstinência, seja como regra, norma ou meta terapêutica, o sentido de universalidade de acesso encontra-se condicionado e a clínica se vê reduzida ao objetivo de remissão de sintoma. Isso em si não é algo exclusivo da abstinência, uma vez que qualquer serviço ou rede de atenção em saúde possui condicionantes, mesmo num sistema universal. Em que medida a abstinência como condição para todos os usuários de drogas gera inevitavelmente uma limitação de direito e acaba por impor, não somente condições, mas restrições ao acesso?

Em uma suposta reunião entre gestores para definir os caminhos da política de saúde para usuário de drogas num determinado estado brasileiro debateu-se sobre ao atual documento (portaria) que define as diretrizes para implementação das Redes de Atenção Psicossocial: "como pode constar neste documento que a Redução de Danos será uma diretriz? Quer dizer que os usuários de drogas vão poder circular livremente usando drogas na instituição? Na minha instituição são realizados exames de urina diariamente para impedir que os usuários usem drogas durante o tratamento" A pergunta que veio desta arguição foi a seguinte: "e o que acontece com os usuários que não aderiram à proposta de abstinência? Voltarão para as cracolândias sem nenhum tipo de cuidado em saúde? O SUS como um sistema de saúde universal não pode deixar de prestar atendimento para a parcela da população que não adere à proposta da abstinência". 
A abstinência como regra absoluta insere o sentido de universal proibicionista, operando como um conceito que agencia um conjunto de pretensos universais: uma concepção universal de saúde como sinônimo de vida livre das drogas, o universal de que as drogas fazem necessariamente mal a saúde, um universal de que todos devem para de usar drogas. Segundo Jullien (2010) a noção de universalidade surge de três impulsos da história humana, que não possuem genealogias em comum. O primeiro é a noção de universalidade do conhecimento, surgido da filosofia pré-socrática, em que o conhecimento verdadeiro surge do afastamento das singularidades e do caos da experiência. Essa noção de universalidade constituiu uma primeira separação entre universal e singular e foi a base para o conhecimento científico. Uma segunda noção de universalidade vem do direito romano, que constitui as bases para a universalidade do acesso, por exemplo. Um terceiro sentido de universalidade surge com o cristianismo, em que a salvação é posta como um universal, diante do qual devemos agir no presente segundo regras morais que vão garantir no pós-vida a eterna salvação das almas. A abstinência delimita um campo de práticas totais que fazem do universal uma ancora de produções de verdades sobre o homem, sobre a saúde, sobre a vida e define uma regra única para todos os indivíduos. O sentido de singularidade, neste caso fica subsumido a uma regra maior e primeira, o que implica dizer que a singularidade é um modo específico de se aplicar uma regra geral, mas desde que esta singularidade esteja em adequação a esta regra. Trata-se, portanto, de um sentido fraco de singularidade, pois neste caso o singular está submetido ao geral: para cada caso um modo específico de se alcançar a abstinência. Um sentido forte de singularidade deve pressupor uma relação em que o caminho para cada caso tenha como referência a constituição não de um plano geral e universalmente válido, mas um plano de constituição de coletivos e produção do comum. A clínica da redução de danos cria uma potente aliança com a clínica ampliada e compartilhada, pois se torna necessário pensar em projetos terapêuticos singulares que acolham a singularidade de cada caso. (Campos, 1997, 2007a, 2007b; Cunha, 2005; Brasil, 2009) Por outro lado, uma equipe de saúde pode trabalhar na perspectiva da clínica ampliada, ou seja, atento para a subjetividade de cada sujeito e não reduzindo a ação clínica a 
queixa-conduta pautada na doença, até que entre na cena terapêutica a relação com as drogas. É possível e comum que muitas equipes, no momento em que a narrativa da história de vida passa pelo uso de drogas, sejam atravessadas por valores morais que reduzam sua capacidade de acolhimento e escuta. Nesse sentido a clínica ampliada, para que se exerça na sua radicalidade, precisa ser também uma clínica da redução de danos.

$\mathrm{Na}$ experiência concreta da redução de danos para que seja possível abordar a especificidade de cada situação, de cada usuário e de cada história de vida é necessário a existências de espaços de co-gestão (Campos, 2007a, 2007b) que possibilitem o compartilhamento de experiências. O compartilhamento de experiência e posições éticas sobre o cuidado de cada caso implica num exercício de construção de novos parâmetros e critérios que orientam a ação, sem que para isso tenha se partir de uma referência universal que oriente todos os casos para a mesma direção. Esse exercício de por em análise o processo de trabalho constitui um plano de referência imanente a experiência, caso contrário seria o puro caos, ou um puro relativismo. É nesse ponto que vemos uma passagem da noção de universal para a noção de comum. (Spinoza 2009; Negri \& Hardt 2005; Jullien 2010).

O comum implica no compartilhamento de experiências em que as diferentes singularidades possam se expressar. Normalmente somos guiados por uma racionalidade em que o compartilhamento tende a ser apreendido na forma do conjunto, da identificação e da semelhança. O conceito de produção do comum implica em pensarmos uma forma de compartilhamento e cooperação em que justamente a diferença e a singularidade são ao mesmo tempo um efeito do encontro de corpos e o que se busca produzir neste encontro. Não importando tanto as diferenças em si, mas os processos de diferenciação e de constituição de modos de vida singulares. Nessa forma de pensar a produção de referências que guiam as nossas ações são produzidas pelo próprio compartilhamento de experiências e não por um ponto estático além da experiência. A produção do comum implica em processos de construção referências, direções e normas em que novas sensibilidades possam ser ativadas. Qual o momento para se indicar um usuário de crack em situação de rua um tratamento específico para o problema 
de drogas? Quando indicar a um usuário em situação de rua que ele precisa parar de usar drogas? Um tipo de proposição desta natureza, num contexto de rua não pode ser uma regra geral, ou algo que se deseja a todo momento para todos os casos. Isso seria insuportável e frustrante, para os trabalhadores e para os usuários.

Um caso emblemático ocorreu quando uma mulher que usava dez pedras de crack por dia, em média, recebeu de sua tia a notícia de que sua mãe havia falecido. ${ }^{5}$ Essa mulher ficou dias perturbada pois não conseguiu ir ao enterro da própria mãe. Ao longo de uma semana ela passou a usar de trinta a quarenta pedras de crack por dia. Até que num certo dia outro morador de rua, amigo dela, deu um abraço nela e disse -“eu sei que alguma coisa aconteceu contigo, não sei o que foi, mas você está precisando de ajuda porque assim você vai morrer". O homem deu um abraço nela e ela começou a chorar sem parar compulsivamente. Nesse dia essa mulher só pensava no Paulinho, redutor de danos referência para aquele território. Quando, no dia seguinte, o Paulinho chegou fazendo o trabalho de campo ele percebeu que havia algo de diferente com esta mulher. Ele se aproximou dela e os dois começaram a conversar e ele então perguntou sobre tratamento. Nesse momento ele percebeu que seria uma abertura para que ela fosse ao Caps-ad, mas ele avaliou que pelo estado físico dele seria melhor levá-la ao Centro de Saúde para fazer uma avaliação clínica pois ela estava muito debilitada.

Essa passagem expressa bem o processo de produção de direções pautadas não por uma norma geral. Não é possível abordar todos os casos na rua sentando e parando para conversar, como não é possível indicar a todos os usuários uma visita ao Centro de Saúde ou ao Caps-ad. Essa sensibilidade que permite lidar com a singularidade de cada encontro implica na construção de um plano comum, de compartilhamento em que as ações são guiadas por pistas que indicam o momento de ser abordar com mais profundidade, momento de se acompanhar até um CS, momento de se acompanhar até um Caps-ad, momento de dar preservativo. E estas pistas são construídas coletivamente.

Como já afirmamos tentar operar de modo homogeneizante é um desvio do sentido de universalidade. Para Jullien (2010), a universalidade deve se resumir a um operador lógico. Sua aplicação é lógica e formal, não podendo ser efetivada como uma prática totalizante. $\mathrm{O}$ universal não pode ser confundido com total, sob o alto preço 
de ser reduzido a uma tentativa de uniformizar, homogeneizar, quando não em forma de autoritarismo. A universalidade é, portanto, uma referência do que deve ser feito garantir acesso a todos - e não do como deve ser feito. $\mathrm{O}$ como deve ser feito está melhor descrito pela equidade, pela redução de danos, pela clínica ampliada e por outras diretrizes metodológicas. (Brasil, 2008)

A abstinência quando se autointitula como única regra possível torna qualquer outra forma de regra, que não esteja a ela submetida, uma espécie de não regra. Mas ao fazer isso a abstinência compete diretamente com o sentido de universalidade do acesso enquanto um recurso jurídico e estabelece limites ao próprio princípio do SUS. No limite do seu exercício ela buscará incluir a todos, logo para aqueles que não aderem por vontade própria, passam em nome da saúde a serem forçados. A utilização da força, se torna uma consequência operatória do próprio princípio de abstinência. Vemos a abstinência ser o operador, o código de conduta que faz o agenciamento entre o campo da saúde e o campo da segurança e da justiça. A abstinência se torna uma espécie de código totalitário que agencia uma rede institucional sob a alegação de estar a serviço do "fazer o bem".

Não se trata de dizer que esta força compulsória tenha como fonte de irradiação as instituições da saúde e mais de dizer que as instituições de saúde podem ser meios para operacionalizar esta lógica. Não é raro encontrar diversas instituições que pregam a abstinência como única meta possível, alegarem a seu favor que aqueles que não desejam se tratar, ou até mesmo que não desejam parar de usar drogas, não são obrigados a permanecerem em tratamento.

Mas acontece que, malgrado as posições de certas instituições nesta direção, as forças que as constituem não operam exclusivamente do interior destes estabelecimentos, mas de um diagrama de poder em que a abstinência passa a operar como regra mestra que condiciona de fora para dentro a partir de outras forças institucionais. Pois se cabe a determinadas instituições definir seus limites internos, outras forças irão se ocupar de arguir sobre aqueles indivíduos que não aceitaram de forma espontânea o tratamento: a polícia, a justiça, a família, a mídia, a medicina, a igreja são só alguns exemplos de forças que irão arguir sobre o conjunto da população que não aderiu de forma espontânea ao tratamento para se vê 
livre das drogas. A própria regra da abstinência se torna compulsória, na medida em que ela passa a operar sobre o conjunto da população.

Iniciativas de "internação compulsória" e/ou "acolhimento compulsório" para usuários de crack, álcool e outras drogas, correspondem a esta faceta despótica da utilização perversa da universalidade. $\mathrm{O}$ anseio de totalização no campo das práticas são antes de tudo formas autoritárias de governo ou de governos totalitários. É nesse sentido que apontamos que a universalidade só pode ser um operador lógico e não um operador metodológico. Ele tem uma função de princípio, de ser referência incondicional em vista do que diversos movimentos podem em nome da vida se apoiar e afirmar sua singularidade. Mas o contrário bem que pode acontecer: de ser uma referência para que em nome da vida se aplique condutas que apaguem as singularidades, uma vez que a elas são alheias.

Uma medida compulsória não se atenta para as singularidades, para a história de vida de cada sujeito, para o modo específico como o uso de drogas passou a compor com sua vida. Ela se aplica de forma total, igualmente a todos independente de suas opções, modos de vida e escolhas pessoais. Eis o ponto em que o divórcio entre o universal e o singular se torna uma arma perversa em nome da vida, da segurança e da saúde da população; um biopoder.

A emergência da população, ou melhor, da vida da população como objeto de governo (Foucault, 2008, 2009) trouxe um conjunto de novas relações de poder, que nos ajudam a constituir este complexo mapa definido para as políticas de drogas, que tem na abstinência uma norma de conduta. A aproximação entre as análises foucaultianas sobre a vida e as análises sobre os sentidos de universalidade nos trouxe um mapa em que a saúde, enquanto campo de governo dos homens é constantemente regulado por normas que redefinem rumos para as práticas universais.

\section{Conclusões}

A Redução de Danos ao se abrir para o encontro de cada experiência como uma singularidade constitui vínculos afetivos suficientemente consistentes para que a vida que se expressa na relação com as drogas possa criar novas regras que podem ou não incluir as drogas. Esse processo instaura um processo de normatividade, de criação de novas regras de si que emergem do encontro com o outro. Em 
contraponto ao processo de normalização em que abstinência busca impor uma única regra, tornando todos igualmente salvos e curados das drogas.

Os modos de vida devem ser apreendidos na sua contingência, na sua multiplicidade, nas diferenças e nas singularidades. Logo, não cabe ao direito, ou se preferirem ao Estado, a função de totalizar no campo das práticas. $\mathrm{O}$ exercício estatal de totalização no campo das experiências da vida se dará necessariamente sobre a forma do autoritarismo. Quando o universal do direito é acessado por forças autoritárias, passa a valer um sentido de universal enquanto imposição. O "todos" da lei pode ser operado por tecnologias de governo que definem que todos devem ser: saudáveis, livres das drogas, alocados em lugares protegidos, etc. Não estaríamos aqui nos referindo às cenas do higienismos, ou quando, mesmo em nome de um direito universal, se propõe medidas como Internação Compulsória que independem das singularidades de cada vida? A universalidade é apropriada por práticas de dominação num uso despótico do conceito. O efeito inevitável é uma suspensão dos direitos e liberdades individuais, a instauração de um estado de exceção. Estamos o tempo todo às voltas com esta possibilidade de definir como legítima a instauração, quando não de um governo totalitário, de situações em que o uso da força se justifica. Por isso que a defesa da universalidade como função lógica e não prática depende não só de uma compreensão filosófica e epistemológica, mas dos modos como este conceito é acessado. A articulação entre redução de danos e clínica ampliada indicam caminhos promissores para que as práticas de atenção e gestão para usuários de álcool e outras drogas estejam ancoradas no sentido libertador de universalidade, como garantia ao acesso com inclusão das singularidades de cada sujeito.

\section{Notas}

${ }^{1} \mathrm{O}$ artigo é inédito, não apresenta qualquer conflito de interesses e é fruto da tese de Doutorado em Saúde Coletiva pela Unicamp, intitulada “ $A$ norma da abstinência e o dispositivo "drogas": direitos universais em territórios marginais da saúde”, defendida em fevereiro de 2013 pelo primeiro autor, Tadeu de Paula Souza, tendo como Professor Orientador o segundo autor, Dr. Sérgio Resende Carvalho.

2 Este caso foi acompanhado junto a disciplina de saúde coletiva do quinto 
ano de medicina da Unicamp em que eles, com a supervisão dos professores, tem que elaborar um projeto terapêutico singular, a partir de um caso trazido pela equipe de saúde da família. Este material foi fonte da pesquisa de doutorado em Saúde Coletiva-FCMUnicamp (Biopolítica das Drogas e Redução de Danos) e aprovado pelo Comitê de Ética de Pesquisa das Faculdades de Ciências Médicas Unicamp.

${ }^{3}$ Este movimento fica bem descrito no filme Quebrando Tabu e Cortina de Fumaça

4 Foucault, M. Vigiar e Punir, apud Dreyfus e Rabonpw

${ }^{5}$ Este caso foi acompanhado junto a supervisão de redutores de danos do município de Campinas-SP na pesquisa de doutorado em Saúde Coletiva-FCMUnicamp (Biopolítica das Drogas e Redução de Danos) e aprovado pelo Comitê de Ética de Pesquisa das Faculdades de Ciências Médicas Unicamp

\section{Referências}

Araujo, T. (2012). Almanaque das drogas: um guia informal para um debate racional. São Paulo: Editora Leya.
Bastos, F. I. (2003). Redução de danos e saúde coletiva: reflexões a propósito das experiências internacional e brasileira. In $\mathrm{C}$. Sampaio \& M. Campos (Orgs.). Drogas, dignidade e inclusão social. A lei e a prática de redução de danos. (pp. 15-44). Rio de Janeiro: ABORDA.

Brasil. (2003). A política do ministério da saúde para atenção integral a usuários de álcool e ouras drogas. Brasília: Ministério da Saúde.

(2008). Humanizasus: documento base para gestores $e$ trabalhadores do sus. Brasília: Ministério da Saúde. - (2009). Clínica ampliada e compartilhada. In Brasil. Série Cartilhas Humanizasus. Brasília: Ministério da Saúde.

Campos, G. W. (2007a). Um método para análise e co-gestão de coletivos. São Paulo: Hucitec. . (2007b). Saúde Paideia. São Paulo: Hucitec.

Cunha, G. T. (2005). A construção da clínica ampliada na atenção básica. São Paulo: Hucitec.

Dreyfus, H. L. \& Rabinow, P. (2010). Michel Foucault: uma trajetória filosófica. Rio de Janeiro: Ed. Forense Universitária. 
Escohotado, A. (2005). Historia general de las drogas. Madri: Editora Espasa Calpe.

Foucault, M. (1977). Vigiar e punir. Petrópolis: Ed. Vozes. (2005). Em defesa da sociedade. São Paulo: Ed. Martins Fontes.

(2006). O uso dos prazeres e as tecnologias de si. In M. Foucault. Ditos e Escritos V. (pp. 192-217). Rio de Janeiro: Ed. Forense Universitária. (2008). Nascimento da

Biopolítica. São Paulo: Ed. Martins Fontes.

(2009). Segurança, Território e População. São Paulo: Ed. Martins Fontes.

Foucault, M. \& Deleuze, G. (1986). Os intelectuais e o poder. In $\mathrm{M}$. Foucault. Microfísica do Poder. (pp. 69-78). Rio de Janeiro: Ed. Graal.

Jullien, F. (2009). O diálogo entre as culturas: do universal ao multiculturalismo. Rio de Janeiro: Ed. Zahar.

Negri, A. \& Hardt, M. (2005). Multidão: guerra e democracia na era do império. Rio de Janeiro: Record.

Passos, E. \& Souza, T. P. (2011). Redução de Danos e Saúde
Pública: construções alternativas à política global de guerra às drogas. Psicologia \& Sociedade, 23 (1), 154-162.

Souza, T. P. (2007). Redução de Danos no Brasil: a clínica e a política em movimento. Dissertação de Mestrado. Programa de PósGraduação em Psicologia, Universidade Federal Fluminense, Niterói, RJ.

Spinoza, B. (2009). Ética. Belo Horizonte: Autêntica Editora.

Tedesco, S. \& Souza, T. P. (2009). Territórios da Clínica: redução de danos e os novos percursos éticos para a clínica das drogas. In S. R. Carvalho, S. Ferigato \& M. E. Barros. (Orgs.). Conexões: Saúde Coletiva e Políticas de Subjetividade. (pp. 141-156). São Paulo: Ed. Hucitec.

Wodak, A. (1998). Redução de danos e programa de troca de seringas. In F. I. Bastos et al. (Orgs.). Troca de seringa: drogas $e$ aids. Brasília: Ministério da Saúde.

Tadeu de Paula Souza: Psicólogo e Doutor em Saúde Coletiva pela Unicamp. Consultor do Ministério da Saúde pela Política Nacional de Humanização - PNH.

E-mail: tadeudepaula@gmail.com 
Polis e Psique, Vol.2, Número Temático, 2012 Página| 58

Sergio Resende Carvalho: Professor

Doutor em Saúde Coletiva pelo

Departamento de Saúde Coletiva,

Unicamp.

E-mail: 2srcarvalho@gmail.com 